\title{
Review and Classification of Reliability Indicators for Power Systems with a High Share of Renewable Energy Sources
}

\author{
Evelyn Heylen, Geert Deconinck, Dirk Van Hertem \\ $K U$ Leuven, Department of Electrical Engineering, EnergyVille \\ Kasteelpark Arenberg 10 PB 2445, 3001 Leuven-Heverlee
}

\begin{abstract}
Power systems with a high share of renewable energy sources face new challenges with respect to reliability management. Scientific literature argues that a paradigm shift is needed in terms of reliability management to efficiently integrate a large amount of renewable energy sources and the required flexibility services. Reliability management involves the use of indicators to support system operation and to assess its performance. Many indicators (proposed to be) used in power system reliability management are presented in technical and scientific literature. To coordinate the development, selection and use of indicators in power systems with a high share of renewable energy sources, this paper presents a structured and consistent overview of the characteristics and the scope of indicators currently in use and available in the literature. A transparent way to characterize indicators is proposed. Available indicators are analyzed in terms of the generic properties of an adequate indicator: relevance in the context of evolving reliability management, ease of use, data availability and reliability determined by the data accuracy. Based on this analysis, missing indicators, shortcomings of existing indicators and directions for future work in a practical and scientific context are identified.
\end{abstract}

Keywords: Classification; Indicators; Adequacy; Security; Reliability

\footnotetext{
${ }^{*}$ Corresponding author

Email address: evelyn.heylen@esat.kuleuven.be (Evelyn Heylen)
}

Preprint submitted to Renewable and Sustainable Energy Reviews 
management

\section{Introduction}

Evolutions in power systems, such as the use of renewable energy sources (RES), have resulted in power systems that are used closer to their limits and are more uncertain. The use of RES, such as wind and solar, has increased sig5 nificantly during the past decade and is expected to increase further, especially in Europe 1. 1] Wind and solar power generation are highly variable and uncertain in nature and result in more distributed, local generation, compared to the traditional system with large centralized generation plants. Modest penetration levels of wind and solar, up to 20-30\%, can be integrated reliably, profitably and affordably according to system operators, but once the inherent flexibility that was built in the grid decades ago is reached, variable RES generation faces integration challenges due to excessive curtailment [1]. The distributed, local generation can also lead to power quality problems, amongst others because conventional, thermal generation that provides frequency control is pushed out of the market, and increased system stress due to bi-directional flows. Therefore, flexibility services are required that should be brought to the market in an appropriate way and result in new stakeholders and existing stakeholders that get new roles.

Continued efforts are required to ensure an adequate reliability level of the power system in modern societies, because electricity demand and society's dependence on electricity are continuously increasing. Currently-used deterministic N-1 reliability management is challenged by the complexity and the many interactions, interdependencies and uncertainties in evolving power systems, e.g., how do we deal with off-shore wind in the N-1 criterion? Do we consider no wind in a neighbouring country as an N-1 contingency state? [3]. Coordi-

\footnotetext{
${ }^{1}$ Under Directive 2009/28/EC, in which renewable energy will have to hold a $20 \%$ share in the final European energy demand by 2020 , the target for electricity generation is $34.3 \%$ of total electricity demand provided by renewable energy sources [2].
} 
nating organizations, such as the North American Electric Reliability Corporation (NERC) and the European Network of Transmission System Operators for Electricity (ENTSO-E), are continuously searching to improve standards for reliability management. Scientific literature argues that a paradigm shift so in terms of reliability management is required to integrate renewable energy sources and smart grid technologies in a cost-effective way [4, 5, 6, 7, 8]. They state that probabilistic reliability management based on economic incentives is better suited to meet the current challenges of power systems [5]. Reliability management consists of reliability assessment and reliability control. Reliability control aims at taking appropriate decisions to satisfy the reliability criterion. Reliability assessment focuses on answering three questions: (1) What can go wrong?, (2) How often will it happen? and (3) What are the consequences if it happens? 9. To quantitatively answer the second and the third question, indicators are used. To assure the effectiveness of evolving reliability management, the characteristics and scope of available indicators should be reassessed and priorities in indicator development should be specified.

A large literature, both scientific papers and technical reports, is available about indicators and indices (proposed to be) used in power system reliability management. The literature is not coherent and the applied terminology is not 45 unified, as different terms are used with a similar meaning. More than 15 years ago, Allan and Billinton made a review of existing approaches and measures to evaluate the quality and performance of different power system sectors, such as generation, transmission and distribution. Their discussion of indicators was limited to best practices in probabilistic reliability assessment of systems with more competition and more stakeholders [10. A high level of variable and uncertain RES generation was not the major point of concern at that time. Although appropriate indicators are crucial to evaluate and support evolving reliability management, no paper exists to the best of the authors' knowledge that assesses available indicators in power systems with a high share of RES.

To coordinate the development, selection and use of indicators in power systems with a high share of renewable energy sources, a structured and consistent 
overview of the characteristics and the scope of indicators currently in use and available in the literature is presented. 129 indicators discussed in the scientific literature and in technical reports of system operators and coordinating organizations, such as NERC, ENTSO-E and the Council of European Energy Regulators (CEER), are analyzed. The paper proposes a transparent way to characterize the indicators, which facilitates the assessment of the characteristics, scope and relevance of the available indicators. The relevance, ease of use, data availability and data accuracy of the available indicators are analyzed in the context of evolving reliability management. Based on the executed analysis, missing indicators, potential improvements of existing indicators and directions for future work in a scientific and practical context are revealed.

Section 2 gives a unified definition of the terminology. Section 3 discusses characteristics of indicators, while Section 4 describes different classes of indicators and their characteristics. Section 5 gives an overview of indicators of the different classes based on a literature survey. Section 6 discusses the results of the qualitative analysis verifying whether available indicators are adequate in the context of evolving reliability management. Section 7 concludes the paper.

\section{Definitions}

Literature on power system reliability does not make a clear distinction between the terms measure, metric, index and indicator. The generic definition of a measure is a value quantified against a standard [11, whereas indicators are not related to a standard. Several definitions of the term indicator exist. In general, the term indicator refers to an observable measure that provides insight into a concept that is difficult to measure directly [12]. According to OECD/DAC2 an indicator is "a quantitative or qualitative factor or variable that provides a simple and reliable means to measure achievement or to reflect changes connected to an intervention" [13]. According to the definition adopted

\footnotetext{
${ }^{2}$ OECD/DAC: Organisation for Economic Co-operation and Development/Development Assistance Committee
} 
by USAID 3 an indicator is "a quantitative or qualitative variable that provides reliable means to measure a particular phenomenon or attribute" [14]. However, in the strictest sense, an indicator does not measure. An indicator can be considered as an indication of a measure.

An index is defined as a combination of related indicators that intend to provide means for meaningful and systematic comparisons of performance across programs that are similar in content and/or have the same goals and objectives [15]. It is a scaled composite statistic that aggregates multiple indicators to capture some property in a single number and rank and summarize observations [16, 17].

Metrics put a variable in relation to one or more other dimensions [11. A metric is often used as a general term to describe the method used to measure something, i.e., the resulting values obtained from measuring, as well as a calculated or combined set of indices [18].

Table 1 summarizes the definitions.

Table 1: Summary of the terminology.

\begin{tabular}{|c|c|}
\hline Term & Definition \\
\hline Measure & Value quantified according to standard \\
\hline Indicator & Quantitative or qualitative indication of achievement \\
\hline Index & $\begin{array}{l}\text { Composite statistic based on measures and indicators making it possible to } \\
\text { rank and summarize observations }\end{array}$ \\
\hline Metric & Set of measures, indicators or indices to evaluate a certain property \\
\hline
\end{tabular}

\section{Characteristics of indicators}

Indicators and indices (proposed to be) used in power system reliability management have a multitude of characteristics. This section presents a unified

\footnotetext{
${ }^{3}$ USAID: United States Agency for International Development
} 
characterization of indicators that facilitates the assessment of similarities and differences between indicators and enables their classification. The characterization is determined by the indicator type, the assessment method to evaluate the indicator value and the type of the indicator value.

\subsection{Types of indicators}

Endrenyi distinguished four types of indicators to assess system malfunctioning in a power system reliability context: probabilities, i.e., what is the chance that the system is malfunctioning, frequencies, i.e., how often does the system malfunction, mean durations, i.e., how long lasts the system malfunctioning on average, and expectations of malfunctioning [19. Replacing expectations by magnitude results in a more generic characterization. The magnitude of malfunctioning corresponds to the degree of violation of the boundary of acceptable behavior or the magnitude of the consequences of malfunctioning. To determine the proper functioning of a component or system, a definition of satisfactory behavior is required. Based on this definition, the performance of the system can be determined. Risk is an additional type of indicator, which is particularly of interest in the context of increasing uncertainties in power systems. Risk indicators take into account the probability and severity, i.e., the magnitude of the consequence, of malfunctioning. These different types of indicators can be further subdivided.

\subsubsection{Hierarchical levels}

The hierarchical levels determine the facilities or system on which the indicator is focusing. Traditionally, three hierarchical levels have been distinguished. Hierarchical level I (HLI) focuses on the generation facilities in classical power system reliability literature, whereas hierarchical level II (HLII) considers both the generation and transmission facilities. Hierarchical level III (HLIII) covers the combination of generation, transmission and distribution facilities 20.4 Indicators can be specific for a particular level or can be used at multiple levels.

\footnotetext{
${ }^{4}$ HLIII studies in practice mainly focus on the distribution level to reduce the problem size.
} 
distinction between the three hierarchical levels has diminished.

\subsubsection{Measures}

The main objective of power system reliability management is to obtain a low frequency of inability to serve load with the required quality and a very low

frequency of experiencing spectacular system failures, such as blackouts [20]. To achieve this objective, physical measures, such as voltage, frequency, loading of components and current, should be within limits. Besides respecting the physical limits of the system, cost-effectiveness of reliability management becomes more important. The assessment of cost-effectiveness requires the monitoring of monetary measures.

\subsubsection{Type of the interruption}

Indicators can be differentiated based on the type of the interruption. HLIII indicators make a distinction between types of interruptions based on their duration by defining indicators for sustained interruptions and short or momentary 145 interruptions. This difference is related to the advance notification of consumers 22]. The cost of energy not supplied (CENS) regulation in Norway additionally differentiates the indicators depending on the time of occurrence of the interruption [22].

\subsubsection{Scope of the indicators}

Allan and Billinton define system indicators and load-point indicators [10]. They define system indicators as global indicators representing the behavior of the overall system. Load-point indicators on the contrary focus at individual bulk supply points. They evaluate the impact of a certain reliability decision on a particular bulk supply point. Allan and Billinton explicitly mention the complementarity of system and load-point indicators.

Alternative terms to denote the scope of an indicator are zonal and local indicators. Zonal indicators operate system wide, local indicators by contrast 
focus on a smaller part of the system, such as a component5 a node or a supply

point. Zonal indicators complemented with the local values provide an overall picture of system behavior [24].

The terminology zonal/local indicators is more generic than system/loadpoint indicators. It is better suited to apply in systems with more stakeholders and stakeholders with different roles, because local indicators are not restricted to load points.

\subsubsection{End-user- and system-related indicators}

Different indicators are used if different entities are studied, i.e., the endusers or the system itself. End-user-related and system-related indicators can be distinguished. End-user-related indicators focus on the impact of an event on one or more end-users. Local end-user-related indicators represent the performance of a particular end-user or end-users of a load point or region, whereas zonal end-user-related indicators consider all end-users in the system. Systemrelated indicators on the contrary quantify system-related concepts, such as voltage, current and frequency. Local system-related indicators focus on parts of the system, e.g., a single component or node in the system, whereas zonal system-related indicators look at the overall system.

\subsubsection{Mono-, bi- and multi-parametric indicators}

Indicators can be characterized based on the number of statistical parameters they express. Mono-parametric indicators employ a single statistical parameter, whereas bi-parametric indicators are expressed by two statistical parameters 25]. A frequency and duration indicator for instance gives information on the average rate a specific state is encountered and the average residence time in a specific state 25. Moreover, multi-parametric indicators exist that express more than two statistical parameters, .

\footnotetext{
${ }^{5} \mathrm{~A}$ component is a device which performs a major operating function and which is regarded as an entity for purposes of recording and analyzing data on outage occurrences, such as a transformer, series capacitors or reactors etc. [23].
} 


\subsubsection{Activity and outcome indicators}

Activity and outcome indicators look at the actions taken in system operation and their consequences. Activity indicators give information on the level of targeted activities to improve reliability, whereas outcome indicators measure 
whether the targeted activity has led to an improved reliability level [12].

Indicator values are the result of a short-term or long-term reliability assessment. A short-term reliability assessment can be dynamic, pseudo-dynamic or static and typically spans seconds up to hours [29, 30]. It typically focuses on the composite generation and transmission level (HLII). A long-term reliability assessment is more high level and focusses on the generation level (HLI), the composite generation and transmission level (HLII) or the distribution level (HLIII). A long-term assessment is typically static in nature and can span years up to decades.

\subsection{Types of indicator values}

The focus of the assessment and the risk aversion of the decision maker determines the type of the indicator value that is of interest. Types of indicator values are maximal or minimal values, average/mean values, expected values, probability density functions, instantaneous values, value at risk, conditional value at risk, etc. Also the period over which the indicator is evaluated can differ, distinguishing annual, monthly, daily, hourly or instantaneous indicators or indicators focussing on a particular period in the year, the worst period for instance [21]. Moreover, a distinction can be made between annual and annualized indicators 24]. The type of the indicator value that can be obtained and the type of the assessment that is applied are interrelated.

\section{Classification of indicators and their characteristics}

Power system reliability is defined as the ability of an electric power system to perform a required function under given conditions for a given time interval [31. It quantifies the ability of a power system to provide an adequate supply of electrical energy satisfying the consumer requirements with few interruptions over an extended period of time. Power system reliability consists of power system adequacy and power system security [32]. An adequate power system 
has sufficient generation, transmission and distribution facilities to satisfy the aggregate electric power and energy requirements of consumers at all times, taking into account scheduled and unscheduled outages of system components 20] ${ }^{6}$ System security on the contrary describes the ability of the system to handle disturbances, such as the loss of major generation units or transmission facilities [20]. Power system security and adequacy are however interdependent, since adequacy is subject to transitions between different states, which are in the strict sense no part of the adequacy analysis, but of the security analysis [10]. Adequacy and security of a power system are interlinked with its coping capacity. The coping capacity represents the ability of the operator and the power system itself to cope with an unwanted event, limit negative effects and restore the power system's function to a normal state [34. The coping capacity of the power system together with its susceptibility determine the power system's vulnerability to external threats that can lead to failure modes. If a realized threat leads to an unwanted event in the power system, it is susceptible to this threat. The increasing uncertainty in power systems due to a high share of RES increases the potential threats the system is facing, e.g., due to forecast errors and variability of RES generation. The power system's vulnerability is an expression of the problem the system faces to maintain its function if a threat leads to an unwanted event and the difficulties to resume its activities after the event occurred [34. Vulnerability is an inherent characteristic of the system and depends on the working force of the system operator, its organizational structure and the technical aspects of the system, such as the availability of the components, which is determined by their reliability and maintainability 35,7 The reliability of the system is determined by its vulnerability, the threats it is facing and the reliability criterion that is applied. The interlinking between the

\footnotetext{
${ }^{6}$ The North American Reliability corporation (NERC) denotes security as operational reliability 33 .

${ }^{7}$ Maintainability is defined as the probability of performing a successful repair action within a given time 31.
} 
aspects determining the system's reliability level are indicated in Fig. 1.

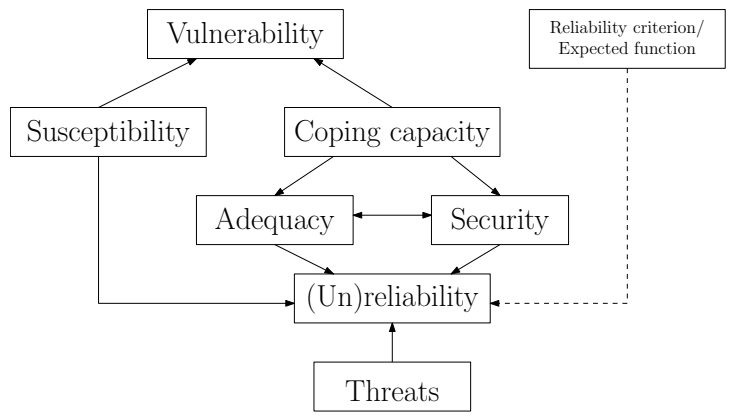

Figure 1: Interaction between different aspects determining reliability of power systems

Literature typically distinguishes adequacy, security and reliability indicators. Moreover, socio-economic indicators gain importance in more advanced, probabilistic reliability management approaches and criteria based on economic principles [36]. Besides these classes of indicators, Hofmann et al. [35] formulate high level indicators for monitoring vulnerability. They make a distinction between indices for coping capacity, criticality, threats and susceptibility. Indicators for threats and susceptibility are divided in classes: natural hazard, human threats and operational conditions.

This section discusses the four main classes of indicators: adequacy, security, socio-economic and reliability indicators. We attribute characteristics to each of the classes to facilitate the classification and characterization of indicators available in literature.

\subsection{Adequacy indicators}

Adequacy indicators represent the ability of an electric power system to supply the aggregate electric power and energy required by the consumers, under steady-state conditions, with system component current ratings not exceeded, bus voltages and system frequency maintained within tolerances, taking into account planned and unplanned system component outages [31. Adequacy indicators focus on the end-users rather than the system or individual components. They are the result of a steady-state assessment and are physical rather than 
socio-economic in nature. Adequacy indicators exist for the three hierarchical

[7, 38. Socio-economic indicators cover all types of costs, benefits or surpluses 
of individual power system stakeholders or an aggregated system. Power system stakeholders currently impacted by power system reliability are electricity generators, system operators, end-consumers, the government and the environment, all facing different types of costs and benefits. Given the challenges power systems with a large share of RES are facing, additional stakeholders, such as flexibility providers, might be integrated in the system or existing stakeholders might get new roles.

Table 2 gives a high-level representation of socio-economic interactions between consumers, producers and system operators. Each of these stakeholders has its own balance, while the interactions between them result in an overall system balance. The upper and lower part of the table make a distinction between respectively system costs and cost transfers. System costs and benefits have resp. a negative and positive effect on socio-economic surplus, which is defined as the sum of surplus or utility of all stakeholders, including external costs and benefits (e.g., environmental costs), over the expected operating range [39. Cost transfers on the contrary appear as costs to a certain stakeholder, while being a payment, and thus benefit, to another stakeholder. They do not affect the socio-economic surplus.

Socio-economic indicators can be deterministic or probabilistic. Both socioeconomic activity and outcome indicators exist. Socio-economic indicators mainly represent a risk or a magnitude and can focus on the system, the end-user or both. Socio-economic indicators are evaluated using a long-term or a short-term assessment.

\subsection{Reliability indices}

The definition of reliability indices differs between different sources. In [31, reliability indices are defined as a measure of the probability that an item or system can perform as required, without failure, for a given time interva 8 under

\footnotetext{
${ }^{8}$ The time interval duration may be expressed in units appropriate to the item concerned, e.g. calendar time, operating cycles, distance run, etc., and the units should always be clearly
} 
Table 2: Overview of cost and benefits of, and socio-economic interactions between, power system stakeholders resulting in an overall system balance [39]

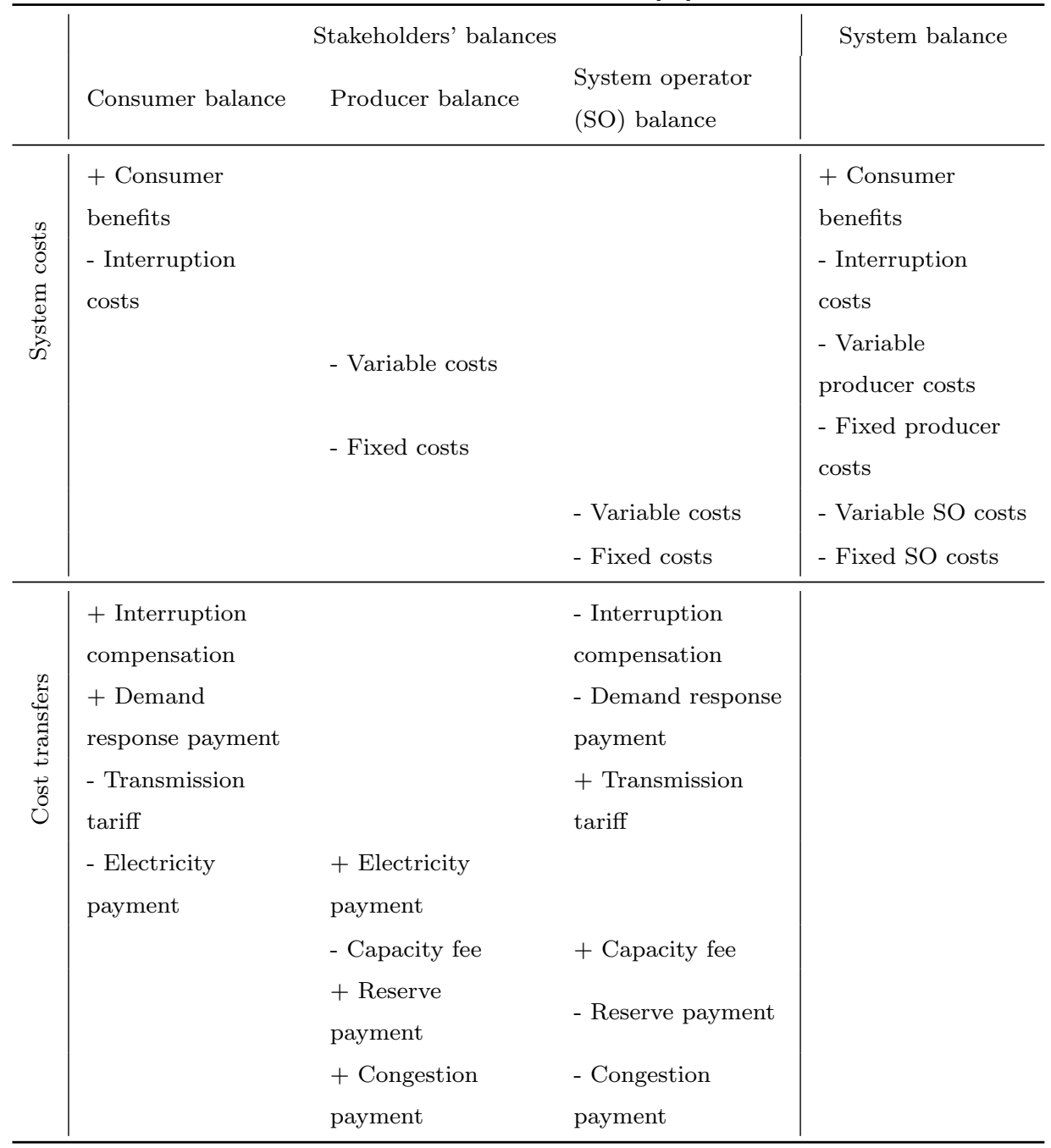



durations, frequencies and probabilities.

NERC defines reliability as "an electricity service level or the degree of performance of the bulk power system defined by accepted standards and other public criteria". Reliability indices are thus also denoted as reliability performance indices. A reliability performance index summarizes the reliability performance with regards to the reliability criterion and reliability standards. The reliability performance depends on the one hand on how the system is loaded in comparison to its limits and the reliability standards and on the other hand on the reliability of each of its individual components. Therefore, reliability indices state analysis and focusing on loss of load is not that clear from their definition. This distinction depends on the type of assessment. Some of the indicators denoted in literature as security indicators can also be classified as HLII adequacy indicators. This is indicated by $(\mathrm{x})$ in Table 3. Multiple ' $\mathrm{x}$ ' in the same section 370 teristics related to that section. It does not mean that all characteristics need

stated 31 .

${ }^{9}$ Given conditions include aspects that affect reliability, such as mode of operation, environmental conditions and maintenance, where applicable [31]. 
to be present at the same time.

Table 3: Characteristics of different classes of indicators

\begin{tabular}{l|cc|cc|cc|ccc}
\hline Indicators & $(1)$ & $(2)$ & $(3)$ & $(4)$ & $(5)$ & $(6)$ & $(7)$ & $(8)$ & $(9)$ \\
\hline Adequacy & $\mathrm{o}$ & $\mathrm{x}$ & $\mathrm{x}$ & $\mathrm{o}$ & $\mathrm{o}$ & $\mathrm{x}$ & $\mathrm{x}$ & $\mathrm{x}$ & $\mathrm{x}$ \\
Security & $\mathrm{x}$ & $\mathrm{o}$ & $\mathrm{x}$ & $\mathrm{o}$ & $\mathrm{x}$ & $(\mathrm{x})$ & $\mathrm{o}$ & $\mathrm{x}$ & $\mathrm{o}$ \\
Socio-economic & $\mathrm{x}$ & $\mathrm{x}$ & $\mathrm{o}$ & $\mathrm{x}$ & $\mathrm{x}$ & $\mathrm{x}$ & $\mathrm{o}$ & $\mathrm{x}$ & $\mathrm{x}$ \\
Reliability & $\mathrm{x}$ & $\mathrm{x}$ & $\mathrm{x}$ & $\mathrm{x}$ & $\mathrm{x}$ & $\mathrm{x}$ & $\mathrm{x}$ & $\mathrm{x}$ & $\mathrm{x}$ \\
\hline
\end{tabular}

(1) Short term, (2) Long term, (3) Physical, (4) Socio-economic, (5) System, (6) End-user,

(7) HLI, (8) HLII, (9) HLIII

$\mathrm{o}=$ not applicable, $\mathrm{x}=$ can be applicable

\section{Overview and classification of indicators}

A multitude of indicators and indices is presented and described in literature, ranging from indicators and indices used in a practical context to more theoretical indicators and indices that are suggested for future reliability management. This section gives an overview of practical indicators and indices prescribed by ENTSO-E and NERC or discussed by the CEER, as well as theoretical indicators and indices discussed in scientific literature. The indicators and indices are assessed based on the characteristics discussed in Section 3 and are assigned to the classes discussed in Section 4

\subsection{Adequacy indicators}

NERC prescribes to evaluate HLI resource adequacy probabilistically based upon reserve margin projections and emerging risks that have been identified in a long-term reliability assessment. The long-term reliability assessment is a peak-driven, deterministic approach to gage resource adequacy. Complementary to the deterministic approach, NERC defines five probabilistic adequacy indices in their guidelines [40, 41].

- Expected unserved energy (EUE): A measure of the resource availability 
planning criteria [MWh]. The expected amount of energy not supplied by the generating system during the period of observation, due to capacity deficiency [42].

- Loss-of-load hours (LOLH): The expected number of hours per year when a system's hourly demand is projected to exceed the generating capacity.

- Loss-of-load expectation ${ }^{10}$ (LOLE): The expected number of days per year for which the available generation capacity is insufficient to serve the daily peak demand.

- Loss-of-load probability (LOLP): The probability of system daily peak or hourly demand exceeding the available generating capacity during a given period.

- Loss-of-load events (LOLEV): The number of events in which some system load is not served in a given year.

To verify the HLII adequacy and security, NERC defines an Adequate Level of Reliability (ALR) in terms of reliability standards [33, ${ }^{11}$ The objective is to obtain standards that balance the cost of risk mitigation and the cost of risk itself. To verify the reliability standards and to provide feedback for improving them, system performance metrics are defined 12 Part of NERC's indicators in the system performance metric to verify the adequate level of reliability are adequacy oriented:

- ALR1-3: Planning reserve margin.

\footnotetext{
${ }^{10}$ Sometimes also denoted as Loss of Load Expectancy.

${ }^{11}$ NERC's definition of Adequate Level of Reliability is continuously updated. The most recent information can be found at https://www.nerc.com/comm/Other/Pages/Adequate\% 20Level\%20of\%20Reliability\%20Task\%20Force\%20ALRTF.aspx [accessed 16 August 2018].

${ }^{12} \mathrm{~A}$ more detailed definition and description of each of the different ALR indices can be found at https://www.nerc. com/comm/PC/Pages/Performance\%20Analysis $\% 20$ Subcommittee $\%$ 20(PAS)/Approved-Metrics .aspx [Accessed 16 August 2018]
} 
- ALR6-2: Energy emergency alert 3 (firm load interruptions due to capacity and energy deficiencies).

- ALR6-3: Energy emergency alert 2 (deficient capacity and energy during peak load periods).

The other indicators are mainly system security oriented.

ENTSO-E's approach for system adequacy assessment was initially deterministic. It was based on the point with the highest load. Due to the increasing penetration of RES and the increasing uncertainty that comes with it, a gradual movement towards a probabilistic approach is initiated with ENTSO-E's target methodology for adequacy assessment [43]. This methodology proposes to use a set of 5 indicators in a generation adequacy assessment. Besides LOLE and LOLP, which are also proposed by NERC, these indicators are:

- Full load hours of generation: The time needed to produce the total en425 ergy under full load conditions of the generators, which represents the utilization rate of the generation park.

- RES curtailment: Amount of energy from renewable energy sources that cannot be produced due to security reasons.

- $\mathrm{CO}_{2}$ emissions: Amount of $\mathrm{CO}_{2}$ emissions. 

expected unserved energy (EUE) ${ }^{14}$ are frequently used for adequacy assessment in practice. They are suggested by NERC and also used in Belgium, Finland, France, Great Brittain, Hungary, Ireland and the Netherlands in a probabilistic assessment to verify generation adequacy. Also in scientific literature, these indicators are suggested [10, 45. Newell et al. propose to use normalized expected unserved energy (EUE) for setting the resource adequacy standard, because it is a more robust and meaningful measure of reliability that can be compared across systems of many sizes, load shapes and uncertainty factors [46. In Spain and Sweden, generation adequacy is verified in terms of the capacity margin, which is a deterministic indicator [21, 47, 15 This is a very simple indicator, but not appropriate in systems with a significant amount of intermittent generation [27.

\footnotetext{
${ }^{13}$ The definition of LOLE differs between sources. NERC defines LOLE as the expected number of days per year with a deficiency calculated based on the peak load per day or a load curve 40. In Europe, LOLE is defined as the expected number of hours per year during which it will not be possible for all the generation resources available to the system to cover the load, even taking into account the interconnections [27]. The latter is equivalent to the LOLH defined by NERC or can also have the notion of an hourly LOLE. A frequently used LOLE threshold is the industry-accepted reliability standard of 1 day in 10 years or 0.1 days/year [44. It is important to notice that this does not corresponds to a LOLH of $2.4 \mathrm{~h} /$ year, because the LOLH corresponding to a LOLE of 0.1 days/year can be significantly higher.

${ }^{14}$ Sometimes also denoted as loss of energy expectation (LOEE) or expected energy not supplied/served (EENS) in a generation adequacy context, which have the same definition [10. A slight difference with EENS is that EENS is not only used in a generation adequacy context, but is also applied on the HLII and HLIII level. The distinction depends on the primary cause of the interruption, which can be lack of power (HLI), lack of interconnection (HLI and HLII), line overload (HLII) or network splitting or isolated nodes (HLII). A drawback of EENS is that it cannot be used to compare different systems. This requires a normalization [27.

${ }^{15}$ Capacity margin is defined as the proportion by which the total expected available generation exceeds the maximum expected level of electricity demand, at the time at which that demand occurs 48 .
} 
Adequacy assessment of the transmission system (HLII) is the responsibility of the individual countries in Europe [27. Indicators used by system operators

- Expected energy not supplied (EENS): The expected total summated energy not supplied to any of the load buses irrespective of the cause and the location of the deficiency.

- Energy index of unreliability (EIU): EENS normalized by the total energy demanded.

- Energy index of reliability (EIR): EIR = 1-EIU.

- System minutes: EENS normalized by peak demand representing equivalent minutes of unavailability.

- $\operatorname{LOLE}_{P 95}$ : The number of hours during which load cannot be covered by all available means in a very cold winter, i.e., a critical scenario.

- Average interruption time (AIT): A measure for the amount of time the supply is interrupted, expressed as the total number of minutes that the power supply is interrupted during the year [27].

A set of other local and zonal indices that can be used in composite generation and transmission system evaluation (HLII) is proposed in [10] and [45].

Adequacy indicators that can be used on HLIII are discussed by Allan and Billinton [10]. Moreover, an IEEE standard is created focussing on distribution adequacy indicators [49]. Although these indicators are referred to as reliability indices in [49, their main focus is on adequacy aspects. Most commonly-used adequacy indicators on the distribution level (HLIII) in Europe are SAIFI and SAID ${ }^{16}$ 50.

\footnotetext{
${ }^{16}$ SAIFI stands for System Average Interruption Frequency Index, which represents the number of consumer interruptions divided by the number of consumers served, while SAIDI stands for System Average Interruption Duration Index and represents the sum of consumersustained outage minutes per year divided by the number of consumers served [27].
} 
An overview and characterization of the different adequacy indicators is given in Table 4. Existing literature makes a clear distinction between the different hierarchical levels. However, due to the increasing amount of distributed generation, the distinction is blurred in practice and composite evaluations are more important.

Table 4: Characterization of adequacy indicators

\begin{tabular}{|c|c|c|c|c|c|c|c|c|c|c|}
\hline Indicators & (1) & $(2)$ & (3) & (4) & $(5)$ & (6) & $(7)$ & (8) & (9) & Reference \\
\hline $\begin{array}{l}\text { LOEE } \\
\text { EENS } \\
\text { EIR } \\
\text { EIU } \\
\text { System minutes } \\
\text { EUE }\end{array}$ & $\mathrm{x}$ & o & o & o & o & $\mathrm{x}$ & $\mathrm{x}$ & o & o & $\begin{array}{c}10 \\
10 \\
10 \\
10 \\
10 \\
10 \\
\text { NERC, } 10,46,47\end{array}$ \\
\hline $\begin{array}{l}\text { LOLH } \\
\text { Loss of load duration (LOLD) }\end{array}$ & o & o & o & $\mathrm{x}$ & o & $\mathrm{x}$ & $\mathrm{x}$ & o & o & $\begin{array}{c}\text { NERC, } 10 \\
51\end{array}$ \\
\hline $\begin{array}{l}\text { Maximum load curtailed } \\
\text { Maximum energy curtailed } \\
\text { Average load cur- } \\
\text { tailed/curtailment } \\
\text { Average energy not sup- } \\
\text { plied/curtailment } \\
\text { Average load cur- } \\
\text { tailed/load point } \\
\text { Average energy cur- } \\
\text { tailed/load point } \\
\text { Maximum system load cur- } \\
\text { tailed under any contin- } \\
\text { gency condition } \\
\text { Maximum system en- } \\
\text { ergy not supplied un- } \\
\text { der any contingency condition }\end{array}$ & $\mathrm{x}$ & o & o & o & $\mathrm{x}$ & o & o & $\mathrm{x}$ & o & 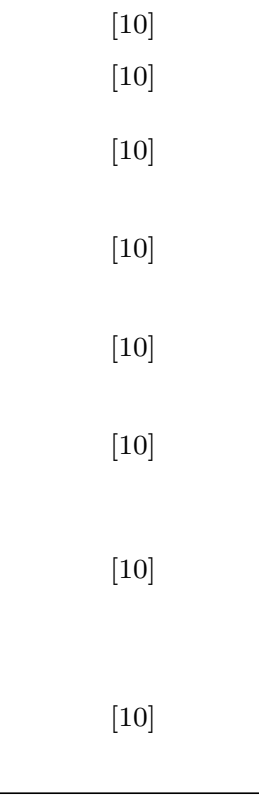 \\
\hline $\begin{array}{l}\text { Expected load curtailed } \\
\text { Expected demand not supplied } \\
\text { EENS }\end{array}$ & $\mathrm{x}$ & o & o & o & o & $\mathrm{x}$ & $\mathrm{o}$ & $\mathrm{x}$ & o & $\begin{array}{l}10 \\
151 \\
10 \\
\end{array}$ \\
\hline
\end{tabular}




\begin{tabular}{|c|c|c|c|c|c|c|c|c|c|c|}
\hline $\begin{array}{l}\text { Modified bulk power en- } \\
\text { ergy curtailment index } \\
\text { System minutes }\end{array}$ & & & & & & & & & & $\begin{array}{l}51 \\
10 \\
\end{array}$ \\
\hline $\begin{array}{l}\text { Bulk power interruption index } \\
\text { Bulk power supply aver- } \\
\text { age MW curtail- } \\
\text { ment/disturbance } \\
\text { Bulk power energy curtail- } \\
\text { ment index } \\
\text { ALR1-3 }\end{array}$ & $\mathrm{x}$ & o & $\mathrm{o}$ & $\mathrm{o}$ & $\mathrm{x}$ & $\mathrm{o}$ & o & $\mathrm{x}$ & $\mathrm{o}$ & $\begin{array}{l}51] \\
51] \\
51 \\
\text { NERC }\end{array}$ \\
\hline $\begin{array}{l}\text { System average interruption } \\
\text { frequency index (SAIFI) } \\
\text { Customer average interruption } \\
\text { duration index (CAIFI) } \\
\text { Momentary average } \\
\text { interruption frequency index } \\
\text { (MAIFI) } \\
\text { Momentary average } \\
\text { interruption event frequency } \\
\text { index (MAIFI }{ }_{E} \text { ) } \\
\text { Average system interruption } \\
\text { frequency index (ASIFI) } \\
\text { Transformer SAIFI } \\
\text { Equivalent number of } \\
\text { interruptions related to the } \\
\text { installed capacity (NIEPI) }\end{array}$ & o & o & $\mathrm{x}$ & $\mathrm{o}$ & $\mathrm{x}$ & $\mathrm{o}$ & o & o & $\mathrm{x}$ & 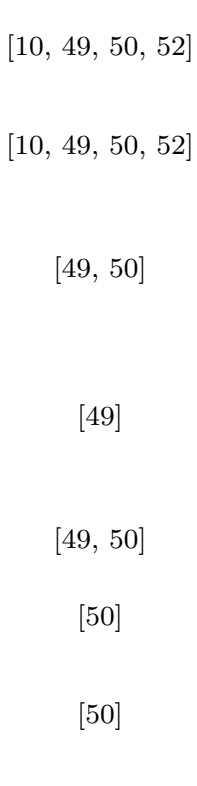 \\
\hline $\begin{array}{l}\text { System average interruption } \\
\text { duration index (SAIDI) } \\
\text { Customer average interruption } \\
\text { duration index (CAIDI) } \\
\text { Outage duration at individ- } \\
\text { ual load point } \\
\text { Customer total average } \\
\text { interruption duration index } \\
\text { (CTAIDI) } \\
\text { Average system interruption } \\
\text { duration index (ASIDI) }\end{array}$ & o & o & $\mathrm{o}$ & $\mathrm{x}$ & $\mathrm{x}$ & o & o & o & $\mathrm{x}$ & $\begin{array}{l}\text { 10, 49, 50, } 52 \text {. } \\
\text { 10, } 49,50,52 \\
\text { 10, } \\
49,50 \\
49,50\end{array}$ \\
\hline Full load hours of generation & $\mathrm{x}$ & $\mathrm{O}$ & & o & $\mathrm{x}$ & $\mathrm{o}$ & $\mathrm{x}$ & $\mathrm{O}$ & $\mathrm{O}$ & ENTSO-E \\
\hline
\end{tabular}




\begin{tabular}{|c|c|c|c|c|c|c|c|c|c|c|}
\hline $\begin{array}{l}\text { RES Curtailment } \\
\mathrm{CO}_{2} \text { Emissions } \\
\text { Generation reserve margin } \\
\text { Percent reserve evaluation } \\
\text { Loss of the largest generat- } \\
\text { ing unit }\end{array}$ & & & & & & & & & & $\begin{array}{c}\text { ENTSO-E } \\
\text { ENTSO-E } \\
21 \\
21 \\
21\end{array}$ \\
\hline $\begin{array}{l}\text { Average service availability } \\
\text { index (ASAI) } \\
\text { Customers experiencing } \\
\text { multiple interruptions }_{\left(\mathrm{CEMI}_{n}\right)} \\
\text { Customer experiencing longest } \\
\text { interruption durations } \\
\text { (CELID) } \\
\text { Customers experiencing } \\
\text { multiple sustained } \\
\text { interruption and momentary } \\
\text { interruption events } \\
\left.\text { (CEMSMI }{ }_{n}\right) \\
\text { Customers experiencing } \\
\text { multiple momentary } \\
\text { interruptions }\left(\mathrm{CEMMI}_{n}\right)\end{array}$ & o & $\mathrm{x}$ & o & o & $\mathrm{x}$ & o & o & o & $\mathrm{x}$ & $\begin{array}{c}10,49,52 \\
49] \\
49 . \\
49 . \\
47 .\end{array}$ \\
\hline $\begin{array}{l}\text { Average En- } \\
\text { ergy ot Served (AENS) } \\
\text { Energy not distributed (END) }\end{array}$ & $\mathrm{x}$ & o & o & o & $\mathrm{x}$ & o & o & o & $\mathrm{x}$ & 10 \\
\hline EENS & $\mathrm{x}$ & o & o & o & o & $\mathrm{x}$ & o & o & $\mathrm{x}$ & 10 \\
\hline $\begin{array}{l}\text { Transformer SAIDI } \\
\text { Equivalent interruption time } \\
\text { related to the installed } \\
\text { capacity (TIEPI) } \\
\text { Customer minutes lost (CML) }\end{array}$ & o & o & o & $\mathrm{x}$ & $\mathrm{x}$ & o & o & o & $\mathrm{x}$ & $\begin{array}{l}50 \\
50 \\
50 \\
50\end{array}$ \\
\hline $\begin{array}{l}\text { Average interrup- } \\
\text { tion time (AIT) } \\
\text { Average interruption dura- } \\
\text { tion (AID) } \\
\text { Average duration of load cur- } \\
\text { tailed/load point }\end{array}$ & o & o & o & $\mathrm{x}$ & $\mathrm{x}$ & o & o & $\mathrm{x}$ & o & $\begin{array}{l}{[50]} \\
50 \\
10 \\
\end{array}$ \\
\hline
\end{tabular}




\begin{tabular}{|c|c|c|c|c|c|c|c|c|c|c|}
\hline $\begin{array}{l}\text { System average restoration in- } \\
\operatorname{dex}(\mathrm{SARI})\end{array}$ & & & & & & & & & & 50 \\
\hline $\begin{array}{l}\text { Average number of curtail- } \\
\text { ments/load point }\end{array}$ & & & & & & & & & & 10 \\
\hline $\begin{array}{l}\text { Average interruption fre- } \\
\text { quency (AIF) }\end{array}$ & o & o & $\mathrm{x}$ & o & $\mathrm{x}$ & o & o & $\mathrm{x}$ & o & 50 \\
\hline ALR6-2 & & & & & & & & & & NERC \\
\hline ALR6-3 & & & & & & & & & & NERC \\
\hline Probability of load curtailment & o & $\mathrm{x}$ & o & $\mathrm{o}$ & o & $\mathrm{x}$ & $\mathrm{o}$ & $\mathrm{x}$ & $\mathrm{o}$ & 51 \\
\hline $\begin{array}{l}\text { Expected dura- } \\
\text { tion of load curtailment } \\
\text { Expected duration of load cur- } \\
\text { tailment (local) }\end{array}$ & o & o & o & $\mathrm{x}$ & o & $\mathrm{x}$ & o & $\mathrm{x}$ & o & $\begin{array}{l}10 \\
51 \\
51\end{array}$ \\
\hline $\begin{array}{l}\text { Expected frequency of failure } \\
\text { Expected number of curtail- } \\
\text { ments (local) }\end{array}$ & o & o & $\mathrm{x}$ & $\mathrm{o}$ & o & $\mathrm{x}$ & $\mathrm{o}$ & $\mathrm{x}$ & o & $\begin{array}{l}10 \\
10 \\
10\end{array}$ \\
\hline $\begin{array}{l}\text { Maximum dura- } \\
\text { tion of load curtailment } \\
\text { Average duration of curtail- } \\
\text { ment/curtailment }\end{array}$ & o & o & o & $\mathrm{x}$ & $\mathrm{x}$ & o & o & $\mathrm{x}$ & o & $\begin{array}{l}10 \\
51 \\
\end{array}$ \\
\hline Failure rate at ind. load point & o & o & $\mathrm{x}$ & o & o & $\mathrm{x}$ & o & o & $\mathrm{x}$ & 10 \\
\hline $\begin{array}{l}\text { Unavailabil- } \\
\text { ity at ind. load point }\end{array}$ & o & $\mathrm{x}$ & $\mathrm{o}$ & $\mathrm{o}$ & o & $\mathrm{x}$ & $\mathrm{o}$ & o & $\mathrm{x}$ & 10 \\
\hline $\begin{array}{l}\text { LOLEV } \\
\text { LOLF } \\
\text { LOLE } \\
\text { LOLE }_{P 95}\end{array}$ & o & o & $\mathrm{x}$ & o & $\mathrm{o}$ & $\mathrm{x}$ & $\mathrm{x}$ & o & o & $\begin{array}{c}\text { NERC } \\
{[51} \\
\text { NERC, ENTSO-E, 10, 47. } \\
27\end{array}$ \\
\hline LOLP & o & $\mathrm{x}$ & o & $\mathrm{o}$ & o & $\mathrm{x}$ & $\mathrm{x}$ & o & o & NERC, ENTSO-E, 10, 47, 53. \\
\hline
\end{tabular}

(1) Magnitude, (2) Probability, (3) Frequency, (4) Duration, (5) Deterministic, (6) Probabilistic, (7) HLI, (8) HLII, (9) HLIII

$\mathrm{o}=$ not applicable, $\mathrm{x}=$ applicable

\subsection{Security indicators}

Besides the adequacy-related standards of the adequate level of reliability discussed in the previous subsection, NERC has defined some security-related 
indicators to verify security-related standards of the adequate level of reliability $33 ! ! 12$ an extended five-state version was proposed by Fink and Carlsen in 1978 [55]. 
Billinton and Khan proposed in 1992 to calculate frequency and probability of being in a particular state as security indicators [56].

In 2015, ENTSO-E started merging the three operational network codes (operational planning and scheduling, operational security and load frequency control and reserve) in a single system operation guideline. This guideline prescribes that in operational planning five indicators should be calculated to count the number of events due to a certain cause that resulted in a degradation of system operation conditions [57]:

- OPS 1A: The number of events per year that result in a degradation of system operation conditions due to an incident on the contingency list;

- OPS 1B: The number of events in OPS 1A caused by an unexpected discrepancy of demand or generation forecasts;

- OPS 2A: The number of events per year that result in a degradation of system operation conditions due to out-of-range contingencies;

- OPS 2B: The number of events in OPS 2A caused by an unexpected discrepancy of demand or generation forecasts;

- OPS 3: The number of events per year that result in a degradation of system operation conditions due to lack of active power reserves.

OPS $1 \mathrm{~B}$ and OPS 2B focus on the impact of uncertainty due to RES and load, which becomes more important in modern power systems.

Besides the indicators for operational planning, a multitude of performance indicators should be reported annually in the context of operational security 525 [57. This set of indicators consists of indicators representing the frequency of an event, as well as indicators representing the duration and/or magnitude of events:

- RT1: Number of tripped transmission system elements per year per TSO;

- RT2: Number of tripped power generation facilities per year per TSO; 
- RT3: Energy not supplied per year due to unscheduled disconnection of demand facilities per TSO;

- RT4: Time duration and number of instances of being in the alert and emergency states per TSO;

- RT5: Time duration and number of events within which there was a lack of reserves identified per TSO;

- RT6: Time duration and number of voltage deviations exceeding the voltage ranges specified in [57;

- RT7: Number of minutes outside the standard frequency range and number of minutes outside the $50 \%$ of maximum steady-state frequency deviation per synchronous area;

- RT8: Number of system-split separations or local blackout states;

- RT9: Number of blackouts involving two or more TSOs.

RT4, RT5 and RT6 are bi-parametric rather than mono-parametric indices, as they include both the duration and frequency of the event.

$\mathrm{Ni}$ et al., Ciapessoni et al. and Dissanayaka et al. proposed some probabilistic security indicators, such as low voltage risk indicator, overload risk indicator, voltage instability risk indicator, cascading risk indicator, overloading risk indicator, high current risk indicator and transient stability risk indicator [4, 58, 59]. These risk indicators combine the magnitude and the probability of a security limit violation. Kirschen et al. have developed a probabilistic indicator of system stress that can be used complementary to the N-1 approach in power system operation. This probabilistic indicator is based on expected energy not served (EENS). It is a probabilistic, leading indicator that allows operators to implement preventive measures and plan corrective measures taking into account probabilities and consequences of contingencies [60].

An overview of the security indicators is given in Table 5 . To evaluate the security indicators, busbar voltages, active power flows, reactive power flows 
and frequency should be monitored [57].

Table 5: Characterization of security indicators

\begin{tabular}{|c|c|c|c|c|c|c|c|c|}
\hline Indicators & $(1)$ & $(2)$ & (3) & (4) & $(5)$ & $(6)$ & (7) & Reference \\
\hline Low voltage risk indicator & & & & & & & & 4 \\
\hline $\begin{array}{l}\text { Voltage instability risk indica- } \\
\text { tor }\end{array}$ & & & & & & & & 4 \\
\hline Cascading risk indicator & $\mathrm{x}$ & O & o & o & $\mathrm{o}$ & 0 & $\mathrm{x}$ & 4 \\
\hline Overloading risk indicator & & & & & & & & 4 \\
\hline High current risk indicator & & & & & & & & 58 \\
\hline $\begin{array}{l}\text { Transient stability risk indica- } \\
\text { tor }\end{array}$ & & & & & & & & 59 \\
\hline Loss of load risk indicator & & & & & & & & 58 \\
\hline Expected energy not served & & & & & & & & 60 \\
\hline ALR1-12 & & & & & & & & NERC \\
\hline ALR6-1 & o & $\mathrm{x}$ & o & o & o & $\mathrm{x}$ & $\mathrm{o}$ & NERC \\
\hline RT3 & & & & & & & & ENTSO-E \\
\hline ALR1-4 & & & & & & & & NERC \\
\hline ALR2-3 & & & & & & & & NERC \\
\hline ALR2-4 & & & & & & & & NERC \\
\hline ALR2-5 & & & & & & & & NERC \\
\hline ALR3-5 & & & & & & & & NERC \\
\hline ALR4-1 & & & & & & & & NERC \\
\hline ALR6-11 & & & & & & & & NERC \\
\hline ALR6-12 & & & & & & & & NERC \\
\hline OPS1A & o & o & o & $\mathrm{x}$ & o & $\mathrm{x}$ & o & ENTSO-E \\
\hline OPS1B & & & & & & & & ENTSO-E \\
\hline OPS2A & & & & & & & & ENTSO-E \\
\hline OPS2B & & & & & & & & ENTSO-E \\
\hline OPS3 & & & & & & & & ENTSO-E \\
\hline RT1 & & & & & & & & ENTSO-E \\
\hline $\mathrm{RT} 2$ & & & & & & & & ENTSO-E \\
\hline RT8 & & & & & & & & ENTSO-E \\
\hline RT9 & & & & & & & & ENTSO-E \\
\hline $\begin{array}{l}\text { Average number of voltage vi- } \\
\text { olations } / \text { load point }^{1}\end{array}$ & & & & & & & & 10 \\
\hline
\end{tabular}




\begin{tabular}{|c|c|c|c|c|c|c|c|c|}
\hline $\begin{array}{l}\text { ALR1-5 } \\
\text { RT7 }\end{array}$ & o & o & o & o & $\mathrm{x}$ & $\mathrm{x}$ & o & $\begin{array}{c}\text { NERC } \\
\text { ENTSO-E }\end{array}$ \\
\hline $\begin{array}{l}\text { Expected number of volt- } \\
\text { age violations }{ }^{1}\end{array}$ & $\mathrm{o}$ & o & o & $\mathrm{x}$ & o & o & $\mathrm{x}$ & 10 \\
\hline RT4 & & & & & & & & ENTSO-E \\
\hline RT5 & o & o & o & $\mathrm{x}$ & $\mathrm{x}$ & $\mathrm{x}$ & o & ENTSO-E \\
\hline RT6 & & & & & & & & ENTSO-E \\
\hline
\end{tabular}

(1) Risk, (2) Magnitude, (3) Probability, (4) Frequency, (5) Duration, (6) Deterministic,

1 This indicator was denoted as an adequacy indicator in [10], however, this does not correspond with the definitions of adequacy and security indicators as adopted in this paper.

\subsection{Socio-economic indicators}

Socio-economic indicators relate power system reliability to social and economic factors. From a socio-economic perspective, the ideal reliability level is obtained at maximal socio-economic surplus 17 Socio-economic surplus is defined as the sum of consumer surplus, producer surplus, TSO surplus and government surplus. The surplus equals the value of a particular reliability level minus the cost to obtain a particular reliability level. Socio-economic surplus maximization equals total system cost minimization under two simplifying assumptions: (i) changes in the electricity market should not change the behaviour of electricity market actors, such as producers and consumers, and (ii) changes in the electricity market should have little effect on other markets [39]18

He et al. denote total system cost as the social cost consisting of the interruption cost and the operating cost. The interruption cost depends on the amount

\footnotetext{
${ }^{17}$ Practical indicators differ from ideal indicators in the sense that practical indicators should be easy to use and all data to calculate the indicator should be available.

${ }^{18}$ These assumptions are never fully met. If, for instance, electricity becomes more expensive and consumers' price elasticity is less than one, consumers will buy less electricity and will have less budget to buy other goods.
} 
of load curtailment and the customer interruption cost function, whereas the operating cost depends on the generated power and the operating cost function of the generators, 61. Besides the generator costs, other costs should be included in the operating cost, such as the cost of line switching, PST tap changing and other reliability actions. Although the cost of these actions is typically lower than the generator costs, it cannot be neglected. Moreover, the operating cost should contain the cost of additional flexibility services that might be required in systems with a high share of RES. As the operating cost focuses on the actions that are taken rather than their outcome, it is denoted as an activity indicator.

Interruption costs have several notions and are based on different parameters. Allan and Billinton specify the customer interruption costs (CIC) and customer outage costs (COC) [10. CICs are interruption costs per interruption and are used to determine the composite and sector customer damage functions (resp. CCDFs and SCDFs). CICs are typically determined based on surveys. COCs at a particular bus can be deduced from the CDFs, the energy consumed by consumers at that bus and failure rates and repair times, i.e., the frequency of the outage and the outage duration. The SCDFs can be converted into global indices of value of lost load (VOLL) or interrupted energy assessment rate (IEAR) 62. VOLL expresses the value of unserved energy at a particular location, type of consumer and moment in time, for a particular duration and a particular type of interruption. It is the marginal interruption cost with respect to energy not supplied, i.e., the interruption cost of an additional 1 MWh interruption [39]. Another indicator that quantifies the value of reliability is the willingness to pay (WTP), which represents the consumers' willingness to pay to improve their continuity of supply 27. VOLL, IEAR and WTP can be considered as criticality indicators, as they are parameters representing how critical reliable electricity supply is for consumers. VOLL is the most widely used indicator of the three and also referred to by ENTSO-E [27, 63].

Based on these criticality indicators, the monetary consequences of interruption for consumers can be estimated. Allan and Billinton define ECOST as the product of IEAR and LOEE and denotes this as expected outage cost. Zhang 
and Billinton on the contrary specify ECOST as the annual expected customer damage cost at a specified system service area or load bus. ECOST is in this case based on the expected energy not supplied (EENS) and the composite customer damage function 64, ${ }^{19}$ Wang and Billinton use the same formula for ECOST as Zhang and Billinton, but they give ECOST two different meanings: 'expected customer interruption cost' and 'total system interruption cost' 65]. In the GARPUR project, (expected) interruption cost is defined as the product of the (expected) energy not supplied and the value of lost load and represent the negative economic impact on electricity consumers of an electricity interruption [39]. This indicator is also denoted as social value of EENS [27.

Table 6: Characterization of socio-economic indicators

\begin{tabular}{|c|c|c|c|c|c|c|c|c|c|c|}
\hline Indicators & (1) & $(2)$ & (3) & $(4)$ & (5) & $(6)$ & $(7)$ & $(8)$ & $(9)$ & Reference \\
\hline $\begin{array}{l}\text { Social welfare/surplus }{ }^{1} \\
\text { Total system } \text { cost }^{1}\end{array}$ & o & $\mathrm{x}$ & o & $\mathrm{O}$ & $\mathrm{O}$ & $\mathrm{x}$ & $\mathrm{x}$ & $\mathrm{x}$ & $\mathrm{O}$ & $\begin{array}{l}39 \\
61\end{array}$ \\
\hline $\begin{array}{l}\text { Customer outage cost } \\
\text { Customer interruption cost }\end{array}$ & o & $\mathrm{x}$ & o & $\mathrm{O}$ & o & o & $\mathrm{x}$ & $\mathrm{x}$ & o & $\begin{array}{l}10 \\
10 \\
\end{array}$ \\
\hline $\begin{array}{l}\text { ECOST } \\
\text { Expected interruption cost } \\
\text { Social value of EENS }\end{array}$ & $\mathrm{x}$ & o & o & o & o & o & $\mathrm{x}$ & o & $\mathrm{x}$ & $\begin{array}{l}\text { [10, 64 65 } \\
\text { 69 } \\
27\end{array}$ \\
\hline Operating cost & $\mathrm{O}$ & $\mathrm{x}$ & o & $\mathrm{O}$ & $\mathrm{O}$ & $\mathrm{x}$ & o & $\mathrm{x}$ & $\mathrm{O}$ & 61 \\
\hline
\end{tabular}

(1) Risk, (2) Magnitude, (3) Probability, (4) Frequency, (5) Duration, (6) System, (7)

End-user, (8) Deterministic, (9) Probabilistic

$\mathrm{o}=$ not applicable, $\mathrm{x}=$ applicable

${ }^{1}$ Both system and end-user related

\subsection{Reliability indices}

NERC's definition of reliability consists of two concepts: adequacy and security. This definition is further refined with the identification of specific characteristics that define an adequate level of reliability (ALR) [33, 66]:

\footnotetext{
${ }^{19}$ LOEE, EENS and EUE are essentially the same [10].
} 
- The system is controlled to stay within acceptable limits during normal conditions.

- The system performs acceptably after credible contingencies.

- The system limits the impact and scope of instability and cascading outages when they occur.

- Facilities are protected from unacceptable damage by operating them within facility ratings.

- Integrity can be restored promptly if it is lost.

- The system has the ability to supply the aggregate electric power and energy requirements of the electricity consumers at all times, taking into account scheduled and reasonably expected unscheduled outages of system components.

635

In 2007, NERC proposed three major indices, which intend to capture and represent multiple reliability parameters in easy-to-understand reliability performance metrics [26, 67]:

- Reliability performance gap: To measure how far the system is from expected performance under contingencies 20

- Adequacy gap: To measure the capacity and energy shortage from expected adequacy level under steady-state conditions ${ }^{21}$

- Violation index: Index based on standardized weights depending on the predefined impact of violating a standard (Violation risk factor (VRF)) and the ex-post assessment of the degree of violation (Violation severity level (VSL)) to measure the reliability improvement from compliance with NERC reliability standards [26].

\footnotetext{
20 http://www.nerc.com/pa/RAPA/PA/Pages/ReliabilityPerformanceGap.aspx

${ }^{21}$ http://www.nerc.com/pa/RAPA/PA/Pages/AdequacyGapQuarterlyView.aspx
} 
In 2010, NERC proposed a severity risk index (SRI) ${ }^{22}$ and an integrated reliability index (IRI). The IRI consists of three risk-based indices: An event driven index (EDI) 69, a condition driven index (CDI) [70 and a standards/statute driven index (SDI) 66]. The event severity risk index is developed to measure the relative severity ranking of events. The relative severity ranking depends on events' occurrence rates and their impact on the bulk power system, which can be among multiple dimensions, e.g. load or facilities. Different events are combined in the EDI. The CDI is an integrated index combining the different ALR indicators in a single index with appropriate weighing factors. To integrate indices that have different units, five trend ratings are identified to quantify each metric's performance level. The SDI verifies the risk of non-compliance with the standards, taking into account the risk of violating the standards and the impact of this violation [66]. The EDI, CDI and SDI are combined in the IRI with appropriate weighting factors. A consultation of power system stakeholders resulted in feedback and comments on the developed indices, such as about the indices' transparency, the practical meaning of the values of the indices and how to react upon them and the values of the weight factors that are used and how to choose them 71 .

Besides the overall reliability level, reliability performance evaluation should also consider the distribution of unreliability among consumers, i.e., the fairness of reliability. To express inequality of the distribution of reliability among consumers in a single value, inequality indices are used. These indices can evaluate part of the social acceptability of reliability decisions. Heylen et al. discuss Gini-based and variance-based inequality indices specified in terms of different adequacy or socio-economic indicators, such as energy not supplied, interruption duration, interruption cost, total cost borne by consumers or RES curtailment. Depending on the applied adequacy or socio-economic indicator, different interpretations of fairness are assessed.

\footnotetext{
${ }^{22}$ Updated in 2014 68.
} 
So far, the main focus was on system-related reliability indices to verify how close the system is loaded to its limits. Moreover, reliability also depends on the individual component reliability. Examples of component reliability indicators are time to repair, operating time between failures, failure rate, failure intensity, etc. [31, 72]. Specific reliability or performance indicators for power plants are defined, such as unit capability factor, unplanned capability loss factor, time availability factor, capacity factor, net electrical energy production, forced outage rate, equivalent forced outage rate and commercial availability. These indicators differ between different types of generating units 21]. A detailed discussion of component reliability indicators is out of the scope of this paper.

Table 7: Characterization of reliability indices

\begin{tabular}{|c|c|c|c|c|c|c|c|c|c|c|}
\hline Indicators & $(1)$ & $(2)$ & $(3)$ & (4) & $(5)$ & $(6)$ & $(7)$ & $(8)$ & $(9)$ & Reference \\
\hline Probability of failure $^{1}$ & o & o & $\mathrm{x}$ & o & o & $\mathrm{x}$ & $\mathrm{O}$ & $\mathrm{O}$ & $\mathrm{x}$ & 10 \\
\hline $\begin{array}{l}\text { Severity risk index } \\
\text { Event driven index }\end{array}$ & $\mathrm{O}$ & $\mathrm{x}$ & $\mathrm{O}$ & $\mathrm{O}$ & $\mathrm{x}$ & $\mathrm{x}$ & $\mathrm{O}$ & $\mathrm{x}$ & o & $\begin{array}{l}\text { NERC } \\
\text { NERC }\end{array}$ \\
\hline Standards/statute driven index & $\mathrm{x}$ & $\mathrm{x}$ & o & o & o & $\mathrm{x}$ & o & $\mathrm{x}$ & o & NERC \\
\hline Condition driven index & $\mathrm{o}$ & $\mathrm{x}$ & o & o & o & $\mathrm{x}$ & $\mathrm{O}$ & $\mathrm{x}$ & o & NERC \\
\hline Inequality of reliability & $\mathrm{O}$ & $\mathrm{x}$ & o & o & o & o & $\mathrm{x}$ & $\mathrm{x}$ & o & 73 \\
\hline Reliability performance gap & & & & & & & & & & NERC \\
\hline Adequacy gap & $\mathrm{o}$ & o & $\mathrm{o}$ & $\mathrm{x}$ & $\mathrm{o}$ & $\mathrm{x}$ & $\mathrm{O}$ & $\mathrm{x}$ & o & NERC \\
\hline Violation index & & & & & & & & & & NERC \\
\hline
\end{tabular}

(1) Risk, (2) Magnitude, (3) Probability, (4) Frequency, (5) Duration, (6) System, (7)

End-user, (8) Deterministic, (9) Probabilistic

$\mathrm{o}=$ not applicable, $\mathrm{x}=$ applicable

Indicators with multiple $\mathrm{x}$ in the same section of the table combine multiple characteristics

1 This indicator is denoted as HLII adequacy indicator in [10, but can be better classified as a reliability index according to the definitions adopted in this paper.

\section{Discussion}

The overall purpose of indicators is to show how the system under study is working, to detect potential problems and assess solutions. Although indicators 
differ between application contexts, effective indicators have common characteristics [74]:

- Relevant: They should measure an important aspect of the system;

- Easy to understand, even by non-experts;

- Based on accessible data: Data to determine the indicator values should be readily available or can be collected with reasonable extra effort;

- Reliable: The information provided by the indicators can be trusted. The reliability of the indicators also depends on the accuracy of the available data.

Important aspects of the system determining the relevance of an indicator relate to the overall objectives of power system operation and the requirements of evolving reliability management. The overall objective of power system operation is specified in the electricity law per country. The Belgian electricity law states for instance that regulation should contribute to the development, in the most cost-effective way, of secure, reliable and efficient, non-discriminating power systems, which are consumer oriented (Art. 23 par. 1.4) 75]. This means that, besides security and adequacy, also cost-effectiveness and the level of discrimination between end-users should be assessed. The requirements and standards of system operation are determined in more detail by the reliability management approach. Scientific literature prescribes that the variability and uncertainty coming with a high share of RES should be adequately considered in future reliability management 6]. Moreover, the characteristics of RES also require the introduction of new flexibility services in power systems to ensure system security and adequacy. Modern technologies that can offer flexibility enable the exploitation of corrective actions in real-time, avoiding unnecessary preventive costs if an appropriate trade-off is made. To make the trade-off between corrective and preventive actions ahead of real time, one should move 715 from deterministic reliability management to probabilistic reliability management based on socio-economic incentives [5]. Besides the fair treatment of end- 
consumers in terms of reliability, flexibility providers and RES generation should also be treated fairly to ensure competition in a liberalized market.

First, this section verifies whether indicators proposed by coordinating organizations, such as NERC, ENTSO-E and CEER, comply with the objectives and requirements of evolving reliability management. Indicators currently applied in practice are assessed in terms of four aspects representing the evolutions in reliability management, i.e., do they adequately represent the uncertainty in the system by being probabilistic in nature, do they assess the cost-effectiveness of system operation, do they assess the reliability for RES or flexibility providers and do they address the discrimination between end-users. Second, indicators proposed in scientific literature that can fill the gaps are discussed and analyzed in terms of their data requirements and data availability and accuracy. Based on this analysis, directions for future work are identified.

\subsection{Indicators proposed by coordinating organizations}

Table 8 summarizes the scope of the security indicators proposed by NERC and ENTSO-E. These indicators mainly focus on the impact on system parameters, such as voltage and overload, load curtailment or the characteristics of events that have occurred. Economic security indicators have not yet been applied in practice. Currently-used security indicators are lagging and deterministic and are especially suitable to evaluate the decision making ex-post, i.e., if the uncertainty is already reduced, to verify whether reliability standards are satisfied.

Table 8: Scope of security indicators proposed by coordinating organizations (NERC/ENTSOE)

\begin{tabular}{l|cccc}
\hline \multirow{2}{*}{ NERC/ENTSO-E } & \multicolumn{4}{c}{ Consequences } \\
& System parameters & Economic & Curtailment & Characteristics of events \\
\hline Probabilistic & $\mathbf{0 / 0}$ & $\mathbf{0 / 0}$ & $\mathbf{0 / 0}$ & $\mathbf{0 / 0}$ \\
\hline Deterministic & $4 / 2$ & $\mathbf{0 / 0}$ & $1 / 2$ & $5 / 10$ \\
\hline
\end{tabular}


Table 9 summarizes the scope of the adequacy indicators proposed by NERC

Table 9: Scope of adequacy indicators proposed by coordinating organizations (NERC/ENTSO-E)

\begin{tabular}{ll|cc}
\hline NERC/ENTSO-E & & Consumers & RES and flexibility \\
\hline \multirow{2}{*}{ Probabilistic } & Physical & $5 / 2$ & $\mathbf{0 / 0}$ \\
& Economic & $\mathbf{0 / 0}$ & $\mathbf{0 / 0}$ \\
& Discrimination & $\mathbf{0 / 0}$ & $\mathbf{0 / 0}$ \\
\hline \multirow{2}{*}{ Deterministic } & Physical & $3 / \mathbf{0}$ & $\mathbf{0 / 2}$ \\
& Economic & $\mathbf{0 / 0}$ & $\mathbf{0 / 0}$ \\
& Discrimination & $\mathbf{0 / 0}$ & $\mathbf{0 / 0}$ \\
\hline
\end{tabular}

Coordinating organizations recommend to harmonize the adequacy indicators used by TSOs to verify the continuity of supply. CEER suggests to use SAIDI and SAIFI for long interruptions, MAIFI for short interruptions and ENS for interruptions at the transmission level 22. Also the proposal for the Clean Energy Package includes directives to harmonize the risk and reliability assessment. It suggests to monitor the security of electricity supply using EENS ${ }^{23}[\mathrm{GWh} /$ year] and LOLE [h/year] [76].

Besides the security and adequacy indicators, NERC focuses on system performance indicators and moves towards integrated reliability indices, combining

\footnotetext{
${ }^{23}$ EENS directly measures the impact of system stress on the quality of service rather than through indirect indications, such as the magnitude of line overloads or bus undervoltages 60.
} 
different aspects in one value. The advantage of these integrated indices is that focusing on less, well selected indices reduces the complexity of reliability management. However, integrated indices are perceived as less transparent and the values are hard to interpret and react upon adequately. Their practical applicability and usefulness should be proved [71].

Overall, the indicators proposed by coordinating organizations mainly focus on the system security or the impact on consumers. Only two indicators focus on the adequacy of RES and generation, i.e., the RES curtailment and the full load hours of generation proposed by ENTSO-E. The impact of unreliability on flexibility providers, i.e., how often they cannot provide their service to their customers due to network issues, is currently not explicitly assessed. Moreover, the indicators proposed by ENTSO-E, NERC, and CEER are mainly physical indicators and do not assess the cost-effectiveness or the level of discrimination between end-users.

\subsection{Complementary indicators and their data requirements}

Probabilistic, physical indicators, such as the ones proposed in 4, 58, 59, 60. can be used complementary to the currently-used, deterministic security analysis. These probabilistic indicators take uncertainties related to RES and contingencies into account. A challenge of these indicators is that accurate probabilities for ex-ante calculations, such as the probabilities of occurrence of contingencies, are required. Moreover, the proposed indicators do not assess the cost-effectiveness of system operation, although this is important to make an adequate trade-off between preventive and corrective actions in reliability management.

Socio-economic surplus is denoted as the ideal index for reliability management, because it covers overall costs and benefits of different system stakeholders [39]. However, socio-economic surplus is not easy to use in practical reliability assessment and TSO decision making. Not all data needed to evaluate socioeconomic surplus are available at the moment of decision making and some of the data are difficult to obtain. The value of reliability from the customer 
perspective is for instance hard to determine in practice, because the societal worth of electric service reliability is very complex and multi-faceted [77]. Several papers suggest to use total system cost in a system cost minimization as an alternative for socio-economic surplus, as it has similar characteristics under certain assumptions [61, 78, 79, 80]. Studies have shown that reliability management based on expected total cost can result in significant cost savings [5. 36. However, exact values of total system cost are hard to obtain. The different cost terms are sensitive to exogenous factors and need to be estimated if they are not known exactly, which typically leaves room for discussion. Costs of corrective actions are for instance hard to estimate [79. Also exact VOLL data to calculate interruption costs are not easy to obtain, as they differ over time and depend on external conditions [27].

Inexact VOLL data also challenge the calculation of LOLE thresholds based on cost-incentives. The European commission suggests to calculate the LOLE threshold based on the trade-off between the value of lost load and the cost of new entry of a peak power plant 27. The optimal LOLE can be calculated based on:

$$
\text { Optimal LOLE }=\frac{\text { Capital cost }}{\text { VOLL }- \text { Operating cost }}
$$

Although NERC and ENTSO-E had already proposed to use LOLE in a probabilistic adequacy assessment, they do not explicitly mention cost incentives considered in the thresholds and no harmonized European or regional thresholds exist [47. If we calculate the LOLE thresholds back to the assumed VOLL for constant cost data of the peak power plant, VOLL significantly differs between countries. If we assume a capital cost of $€ 60000 / \mathrm{MWh} /$ year and an operating cost of $€ 50 / \mathrm{MWh}$ for the peak power plant, Table 10 summarizes the LOLE thresholds currently used in Europe and their corresponding VOLL. If VOLL is correctly estimated, the cost-effectiveness of the level of redundancy can be considered in the adequacy assessment for average conditions. Detailed VOLL data that differ over time are hard to apply in a LOLE assessment, because LOLE is defined over a period of time. 
Table 10: The LOLE thresholds and their corresponding VOLL

\begin{tabular}{ccc}
\hline LOLE $[\mathrm{h} /$ year $]$ & VOLL $[€ / \mathrm{MWh}]$ & Countries [4] \\
\hline 3 & 20050 & Belgium, France, Great Britain \\
4 & 15050 & The Netherlands \\
8 & 7550 & Republic of Ireland \\
\hline
\end{tabular}

Other socio-economic indicators proposed in scientific literature mainly focus on the magnitude of specific effects and are typically deterministic in nature. Moving towards probabilistic reliability management approaches with cost incentives, either in the objective function or in the constraints, requires probabilistic socio-economic indicators. Probabilistic, socio-economic indicators, expressing the risk in terms of costs or surplus, are useful to ensure costeffectiveness. ECOST is a first step in this direction, but this indicator only focuses on the interruption cost rather than on the total cost.

Besides the magnitude of the socio-economic impact, the importance of fairness is increasingly recognized in the power system literature. Perlaviciute et al. [81] argue that the different drivers for public acceptability, of which fairness is one, should be assessed from the start of a project and during the implementation phase. To verify the fairness of reliability decisions in terms of reliability, system operators and regulators can use inequality indices as proposed in [82].

\subsection{Missing indicators and suggestions for future work}

Based on the analysis of available indicators, four important directions for future work in a practical and scientific context are determined.

First, the preceding assessment of available indicators revealed that no unified terminology exists for the indicators. To avoid confusion about the definitions of the applied indicators, homogenization of the indicator terminology is an important task.

Second, indicator development should focus on probabilistic indicators covering physical and socio-economic aspects. Besides focussing on the end-consumers 
and the system itself, indicators should be developed to assess the adequacy for important field of study.

Third, the discussion of fairness in a power system context in literature is merely theoretical so far [82] Further development of fairness indices towards practically applicable indices requires that government and regulatory agenconsumers' perception of their peers, e.g., are consumers concerned about differences between members of the same consumer group or the same region, and a threshold of the acceptable level of unfairness [83].

Fourth, transmission system operators should analyze how probabilistic security indicators and socio-economic indicators proposed in scientific literature can contribute to system operation by applying them complementary to the current approach. A first step in this direction was made in the GARPUR project, in which the Icelandic TSO Landsnet has experimented with probabilistic reliability assessment in a pilot test 84. The main objective of the pilot test was to verify the feasibility of the probabilistic approach, rather than to estimate potential improvements. Real-time risk information has been provided to the system operators in the control room using probabilistic indicators, such as the risk of interruption cost, the residual risk due to omitted contingency states, probability of one or more faults in the next hour, the probability of being in an acceptable state after one hour and the number of contingencies considered [85. The pilot test showed that the ease of use and the transparency of the indicators are as important as their theoretical relevance and reliability to assure their practical applicability. The operators criticized the lack of transparency in the approach, e.g., what is the specific reason for an increase in risk. Transparency can be provided by optionally offering detailed, qualitative information to the system operator about how the indicator value is obtained [85]. Moreover, transmission system operators have recognized the importance of accurate data, such as failure probabilities, and their deficiencies on the domain of data analysis the last decades. These findings have resulted in the foundation of a 

nett, which is amongst others focussing on the determination of detailed failure probabilities 86 .

\section{Conclusion}

Literature on indicators that can be used in power system reliability management is not coherent nor unified. The presented overview, characterization and classification of indicators provides insight in the available indicators and their characteristics. Four main classes of indicators can be distinguished each with their own characteristics: adequacy, security, socio-economic and reliability indicators.

The set of currently-used adequacy indicators contains deterministic and probabilistic indicators. These adequacy indicators mainly focus on end-consumers' adequacy, whereas indicators to assess the adequacy for flexibility providers are not available in practice or in scientific literature. The set of currently-used security indicators especially lacks probabilistic indicators that adequately represent the uncertainty in power systems resulting from the increasing penetration of renewable energy sources. Currently-used security indicators are mainly deterministic, lagging, physical indicators to assess the security of the system ex-post. Besides the physical indicators, system operators should consider riskbased socio-economic indicators when making a trade-off between preventive and corrective actions to efficiently integrate flexibility resources in future reliability management.

Besides the relevance of indicators in power system operation, the availability and accuracy of the data to calculate the indicator values are important. Not all data to calculate complementary probabilistic and socio-economic indicators are readily available. Probabilistic indicators, as proposed in scientific literature, rely on accurate failure probabilities, which are hard to obtain in practice. Moreover, detailed VOLL data or data about the cost of reliability actions required in socio-economic indicators are also also hard to estimate. 
Future work should focus on further developing risk-based indicators to guide

the decision-making process of reliability management towards secure and costeffective decisions. Increasing focus should be put on the development of indicators to assess the reliability for generators and flexibility providers. Moreover, the ease of use and transparency of the indicators should be considered in the development process to ensure their practical applicability. Besides the definitions of the indicators, a guideline to determine appropriate thresholds for the indicators in different systems is as important.

\section{Acknowledgment}

The work of Evelyn Heylen is supported by the Research Foundation Flanders (FWO).

\section{References}

[1] A. Bloom, U. Helman, H. Holttinen, K. Summers, J. Bakke, G. Brinkman, A. Lopez, It's indisputable: Five facts about planning and operating modern power systems, IEEE Power and Energy Magazine 2017;15;6;22-30.

[2] European Renewable Energy Council, Mapping renewable energy pathways towards 2020., http://www.eufores.org/fileadmin/eufores/ Projects/REPAP_2020/EREC-roadmap-V4.pdf 2011 [accessed 16 August 2018].

[3] E. Heylen, D. Van Hertem, Importance and difficulties of comparing reliability criteria and the assessment of reliability, Young researchers symposium 2014; EESA.

[4] M. Ni, J. D. McCalley, V. Vittal, T. Tayyib, Online risk-based security assessment, IEEE Trans. Power Syst. 2003;18;1;258-65.

[5] G. Strbac, D. S. Kirschen, R. Moreno, Reliability standards for the operation and planning of future electricity networks, Foundations and Trends in Electric Energy Systems 2016;1;3;143-219. 
[6] J. McCalley, S. Asgarpoor, L. Bertling, R. Billinton, H. Chao, J. Chen, J. Endrenyi, R. Fletcher, A. Ford, C. Grigg, G. Hamoud, D. Logan, A. Meliopoulous, M. Ni, N. Rau, L. Salvaderi, M. Schilling, Y. Schlumberger, A. Schneider, C. Singh, Probabilistic security assessment for power system operations, IEEE Power and Energy Society General Meeting 2004.

[7] G. Strbac, S. Ahmed, D. Kirschen, R. Allan, A method for computing the value of corrective security, IEEE Trans. Power Syst. 1998;13;3;1096-102.

[8] F. Xiao, J. D. McCalley, Risk-based security and economy tradeoff analysis for real-time operation, IEEE Trans. Power Syst. 2007;22;4;2287-8.

[9] J. Arcé, M. Ilic, Managing short term reliability related risks, Energy Laboratory Publication MIT EL 00-007 WP 2000.

[10] R. Allan, R. Billinton, Probabilistic assessment of power systems, Proceedings of the IEEE $2000 ; 88 ; 2 ; 140-62$.

[11] D. Bours, What's in a name? on indicators, measures and metrics, https://www.climate-eval.org/blog/ whats-name-indicators-measures-and-metrics 2014 [accessed 16 August 2018].

[12] OECD, Guidance on developing safety performance indicators related to chemical accident prevention, preparedness and response for public authorities and communities/public, https://www.oecd.org/chemicalsafety/ chemical-accidents/41269639.pdf; 2008 [accessed 16 August 2018].

[13] Development Assistance Committee (DAC) Working Party on Aid Evaluation, Glossary of Key Terms in Evaluation and Results Based Management, https://www.oecd.org/dac/evaluation/2754804.pdf 2010 [accessed 16 August 2018].

[14] United States Agency International Development: Planning and Performance Management Unit, Glossary of evaluation terms, 2009. 
[15] Sharing information to improve evaluation: Use measures, indicators or metrics, http://www. betterevaluation.org/en/plan/describe/ measures_indicators, 2017 [accessed 16 August 2018].

[16] E. Babbie, The Practice of Social Research. 13th ed. Belmont USA: Cengage Learning; 2013.

[17] A. Hawken, G. L. Munck, Cross-national indices with gender-differentiated data: What do they measure? how valid are they?, Social Indicators Research 2012; 111;3;801-38.

[18] L. Labate, Metrics, measures and indicators, https://thecarebot. github.io/metrics-measures-and-indicators/, 2017 [accessed $16 \mathrm{Au}-$ gust 2018].

[19] J. Endrenyi, Reliability Modeling in Electric Power Systems. 1st ed. Chichester UK: Wiley; 1979.

[20] R. Billinton, R. N. Allan, Power system reliability in perspective, IET Electronics and Power 1984;30;3;231-6.

[21] M. Cepin, Assessment of power system reliability. 1st ed. London UK: Springer; 2011.

[22] CEER, 6th CEER Benchmarking report on quality of electricity and

a gas supply, http://www.ceer.eu/portal/page/portal/EER_HOME/EER_ PUBLICATIONS/CEER_PAPERS/Cross-Sectoral/2016 2016 [accessed 16 August 2018].

[23] IEEE Standards board, IEEE std. 859-1987 - IEEE Standard Terms for Reporting and Analyzing Outage Occurrences and Outage States of Electrical Transmission Facilities, DOI: 10.1109/IEEESTD.1988.86288; IEEE; 1988.

[24] R. Billinton, R. N. Allan, Reliability of electric systems: An overview In: Hoang Pham, editor. Handbook of Reliability Engineering, 1st ed. London UK: Springer; 2003, p. 512. 
[25] Power Systems Engineering Committee, Reliability indices for use in bulk power supply adequacy evaluation, IEEE Trans. Power App. Syst. 1978;4;1097-103.

[26] NERC, Towards ensuring reliability: Reliability performance metrics, https://www.nerc.com/comm/PC/Performance\%20Analysis\%

口 20Subcommittee\%20PAS\%20DL/Archive/Reliability_Metrics_white_ paper.pdf; 2007 [Accessed 16 August 2018].

[27] European Commission, Identification of appropriate generation and system adequacy standards for the internal electricity mar-

985 ket, https://ec.europa.eu/energy/sites/ener/files/documents/ Generation\%20adequacy\%20Final\%20Report_for\%20publication.pdf; 2016 [accessed 16 August 2018].

[28] GARPUR consortium, D1.1 State of the art on reliability assessment in power systems, https://www.sintef.no/projectweb/garpur/ deliverables/; 2014 [accessed 16 August 2018].

[29] D. Niebur, R. Fischl, Artificial neural networks for static security assessment. In: Warwick K, editor. Artificial intelligence techniques in power systems, 1st ed. London: The Institution of Electrical Engineers; 1997, p $143-191$.

[30] A. Monticelli, M. V. F. Pereira, S. Granville, Security-constrained optimal power flow with post-contingency corrective rescheduling, IEEE Trans. Power Syst. 1987;2;1;175-80.

[31] International Electrotechnical Commission, Electropedia: The world's online electrotechnical vocabulary, http://www.electropedia.org/; 2016 [accessed 16 August 2018].

[32] P. Kundur, J. Paserba, V. Ajjarapu, G. Andersson, A. Bose, C. Canizares, N. Hatziargyriou, D. Hill, A. Stankovic, C. Taylor, et al., Definition and classification of power system stability IEEE/CIGRE joint task force on 
stability terms and definitions, IEEE Trans. Power Syst. 2004;19;3;1387-

[33] NERC, Definition of adequate level of reliability, https://www.nerc.com/ comm/Other/Pages/Adequate\%20Level\%20of\%20Reliability\%20Task\% 20Force\%20ALRTF.aspx; 2007 [accessed 16 August 2018].

[34] G. Kjølle, O. Gjerde, M. Hofmann, Vulnerability and security in a changing

[35] M. Hofmann, G. Kjølle, O. Gjerde, Development of indicators to monitor vulnerabilities in power systems, PSAM11/ESREL2012.

[36] E. Heylen, M. Ovaere, G. Deconinck, S. Proost, D. Van Hertem, A multidimensional analysis of reliability criteria: From deterministic n-1 to a probabilistic approach, Electric Power Systems Research [Unpublished results].

[37] S. Meliopoulos, D. Taylor, C. Singh, F. Yang, S. W. Kang, G. Stefopoulos, Comprehensive power system reliability assessment, PSERC

[38] D. Kirschen, K. Bell, D. Nedic, D. Jayaweera, R. Allan, Computing the value of security, IEE Proceedings Generation, Transmission and Distribution $2003 ; 150 ; 6 ; 673-8$.

[39] GARPUR consortium, D3.1 Quantification method in the absence of market response and with market response taken into account, https://wWw . sintef.no/projectweb/garpur/deliverables/; 2016 [accessed 16 August 2018].

[40] NERC, 2016 probabilistic assessment - technical guideline docu1. ment, https://www.nerc.com/comm/PC/PAITF/ProbA\%20Technical\% 1030 20Guideline\%20Document\%20-\%20Final.pdf 2016 [accessed 16 August 2018]. 
[41] NERC, 2016 probabilistic assessment, https://www.nerc.com/pa/RAPA/

n ra/Reliability\%20Assessments\%20DL/2016ProbA_Report_Final_ March.pdf; 2017 [accessed 16 August 2018].

[47] CEER, Assessment of electricity generation adequacy in Euro11 pean countries, https://www.ceer.eu/documents/104400/-/-/ a9517a5f-5a98-2974-dd61-e085c7971b53; 2014 [accessed 16 August 2018].

[48] Royal Academy of Engineering: Council for Science and Technology, GB 口. electricity capacity margin, https://www.raeng.org.uk/publications/ 
reports/gb-electricity-capacity-margin; 2013 [accessed 16 August 2018].

[49] IEEE standards association, 1366-2012 - IEEE guide for electric power distribution reliability indices, DOI: 10.1109/IEEESTD.2012.6209381; IEEE; 2012 .

[50] CEER, 4th CEER Benchmarking report on quality of electricity supply, http://www.autorita.energia.it/allegati/pubblicazioni/ C08-EQS-24-04_4th_Benchmarking_Report_EQS_10-Dec-2008_re.pdf 2008 [accessed 16 August 2018].

[51] W. Li, R. Billinton, Reliability Assessment of Electrical Power Systems Using Monte Carlo Methods. 1st ed. New York USA: Plenum Press; 1994.

[56] R. Billinton, E. Khan, A security based approach to composite power system reliability evaluation, IEEE Trans. Power Syst. 1992;7;1;65 - 72.

[57] ENTSO-E, System operation guideline, https://ec.europa.eu/energy/ 1. $\quad$ sites/ener/files/documents/SystemOperationGuideline\%20final\% 28provisional\%2904052016.pdf 2016 [accessed 16 August 2018]. 
[62] R. Billinton, J. Oteng-Adjei, Comparison of two alternate methods to establish an interrupted energy assessment rate, IEEE Trans. Power syst. $1987 ; 2 ; 3 ; 751-7$.

[63] ENTSO-E, ENTSO-E Guideline for Cost Benefit Analysis of Grid multiterminal HVDC networks, IFAC Proceedings Volumes 2011;44;1;172732.

[59] A. Dissanayaka, U. D. Annakkage, B. Jayasekara, B. Bagen, Risk-based dynamic security assessment, IEEE Trans. Power Syst. 2011;26;3;1302-8.

60] D. S. Kirschen, D. Jayaweera, D. P. Nedic, R. N. Allan, A probabilistic indicator of system stress, IEEE Trans. Power Syst. 2004;19;3;1650-7.

61] J. He, L. Cheng, D. S. Kirschen, Y. Sun, Optimising the balance between security and economy on a probabilistic basis, IET generation, transmission

20approved $\% 20$ by $\% 20$ the $\% 20$ European $\% 20$ Commission $\% 20$ on $\% 204 \%$ 20February\%202015.pdf; 2015 [accessed 16 August 2018].

[64] W. Zhang, R. Billinton, Cost-related reliability evaluation of interconnected bulk power systems using an equivalent approach, Electric Machines \& Power Systems 2000;28;9;793-810.

[65] P. Wang, R. Billinton, Optimum load-shedding technique to reduce the total customer interruption cost in a distribution system, IEE ProceedingsGeneration, Transmission and Distribution 2000;147;1;51-6.

1110 [66] NERC, Integrated reliability index concepts, https://www.nerc. 
Integrated_Reliability_Index_WhitePaper_DRAFT.pdf 2011 [accessed 16 August 2018].

[67] NERC, Three-year electric reliability organization performance assessment report, https://www.nerc.com/gov/Pages/Three-Year-Performance.

aspx?RootFolder=\%2Fgov\%2FThree\%20Year $\% 20$ Performance $\% 20 \mathrm{DL} \%$

1) 2FThree $\% 20$ Year $\% 20$ Assessment $\% 20 \% 2 \mathrm{D} \% 20 \mathrm{July} \% 201 \% 2 \mathrm{C} \% 202009 \&$

ㅁ. FolderCTID=0x0120007922CA21FD97BE4E9A2F610283C1C9CB\&View = \{D61B00CD-E83E-4E8E-B09E-DDDF44FD9A51\}; 2009 [accessed 16 August 2018].

[68] NERC Performance Analysis Subcommittee, SRI enhancement, https:

[1/www.nerc.com/comm/PC/Performance\%20Analysis\%20Subcommittee\% 20PAS\%202013/SRI\%20Enhancement\%20Whitepaper.pdf; 2014 [accessed 16 August 2018].

[69] NERC, Event driven index, https://www.nerc.com/comm/PC/ Performance\%20Analysis\%20Subcommittee $\% 20$ PAS $\% 20 D L / E D I \_$ Whitepaper.pdf; 2012 [accessed 16 August 2018].

[70] NERC, Metric performance and condition driven index, https:

//WwW.nerc.com/comm/PC/PerformanceAnalysisSubcommitteePASDL/

1130 CDI_Whitepaper.pdf 2012 [accessed 16 August 2018].

[71] NERC, Integrated reliability index (IRI) concepts - comments and re-

11. sponses, https://www.nerc.com/comm/PC/Performance\%20Analysis\% 20Subcommittee\%20PAS\%20DL/Archive/IRI_Whitepaper_Comments.pdf 2011 [accessed 16 August 2018].

[72] R. Billinton, R. N. Allan, Reliability evaluation of power systems. 1st ed. New York USA: Plenum Press; 1984, Vol. 2.

[73] M. Ovaere, E. Heylen, S. Proost, G. Deconinck, D. Van Hertem, How detailed value of lost load data impact power system reliability decisions: 
a trade-off between effciency and equity, KU Leuven Department of Economics Discussion Paper series 2016;16.26.

[74] Sustainable Measures, Characteristics of effective indicators, http://www. sustainablemeasures.com/node/92 [accessed 16 August 2018].

[75] Law regarding the organization of the electricity market, www.ejustice.just.fgov.be/cgi_loi/change_lg.pl?language=nl\& $1 \mathrm{a}=\mathrm{N} \& \mathrm{cn}=1999042942 \& \mathrm{table \_ name=wet}[\mathrm{In}$ Dutch]; 1999 [accessed 16 August 2018].

[76] The European Parliament and the Council, Regulation of the European Parliament and of the Council on risk-preparedness in the electricity sector and repealing, http://eur-lex.europa.eu/legal-content/EN/TXT/ HTML/?uri=CELEX : 52016PC0862\&from=EN; 2016 [accessed 16 August 2018].

[77] L. Goel, Power system reliability cost/benefit assessment and application in perspective, Computers \& electrical engineering 1998;24;5;315-24.

[78] E. Karangelos, L. Wehenkel, Probabilistic reliability management approach and criteria for power system real-time operation, Power systems computation conference 2016 .

[79] F. Capitanescu, J. M. Ramos, P. Panciatici, D. Kirschen, A. M. Marcolini, L. Platbrood, L. Wehenkel, State-of-the-art, challenges, and future trends in security constrained optimal power flow, Electric Power Systems Research $2011 ; 81 ; 8 ; 1731-41$.

[80] J. Condren, T. W. Gedra, P. Damrongkulkamjorn, Optimal power flow with expected security costs, IEEE Trans. Power Syst. 2006;21;2;541-7.

[81] G. Perlaviciute, G. Schuitema, P. Devine-Wright, B. Ram, At the heart of a sustainable energy transition: The public acceptability of energy projects, IEEE Power and Energy Magazine 2018;16;1;49-55. 
[82] E. Heylen, M. Ovaere, G. Deconinck, S. Proost, D. Van Hertem, Fairness and inequality in power system reliability: Summarizing indices, Electric Power Systems Research [Unpublished results].

[83] E. Heylen, M. Ovaere, G. Deconinck, D. Van Hertem, Fair reliability management: Comparing deterministic and probabilistic short-term reliability management, IEEE Power and Energy Society General Meeting 2018.

[84] GARPUR consortium, D8.3 Results from near real life pilot testing (Public Summary), https://www.sintef.no/projectweb/garpur/ deliverables/; 2017 [accessed 16 August 2018].

[85] S. Perkin, Real-time Weather-dependent Probabilistic Reliability Assess1175 ment of the Icelandic Power System, Ph.D. thesis, Reykjavik University 2018.

[86] T. Trötscher, Estimating the probability of failure for over-

1. head lines, https://datascience.statnett.no/2018/04/23/ estimating-probability-of-failure-overhead-line-lightning/;

11802018 [accessed 16 August 2018]. 